Supporting Information for

\title{
Photodetector Arrays Directly Assembled onto Polymer Substrates from Aqueous Solution
}

Fairland F. Amos, Stephen A. Morin, Jeremy A. Streifer, Robert J. Hamers and Song Jin*

Department of Chemistry, University of Wisconsin - Madison, Madison, Wisconsin 53706, USA

*email: jin@chem.wisc.edu 


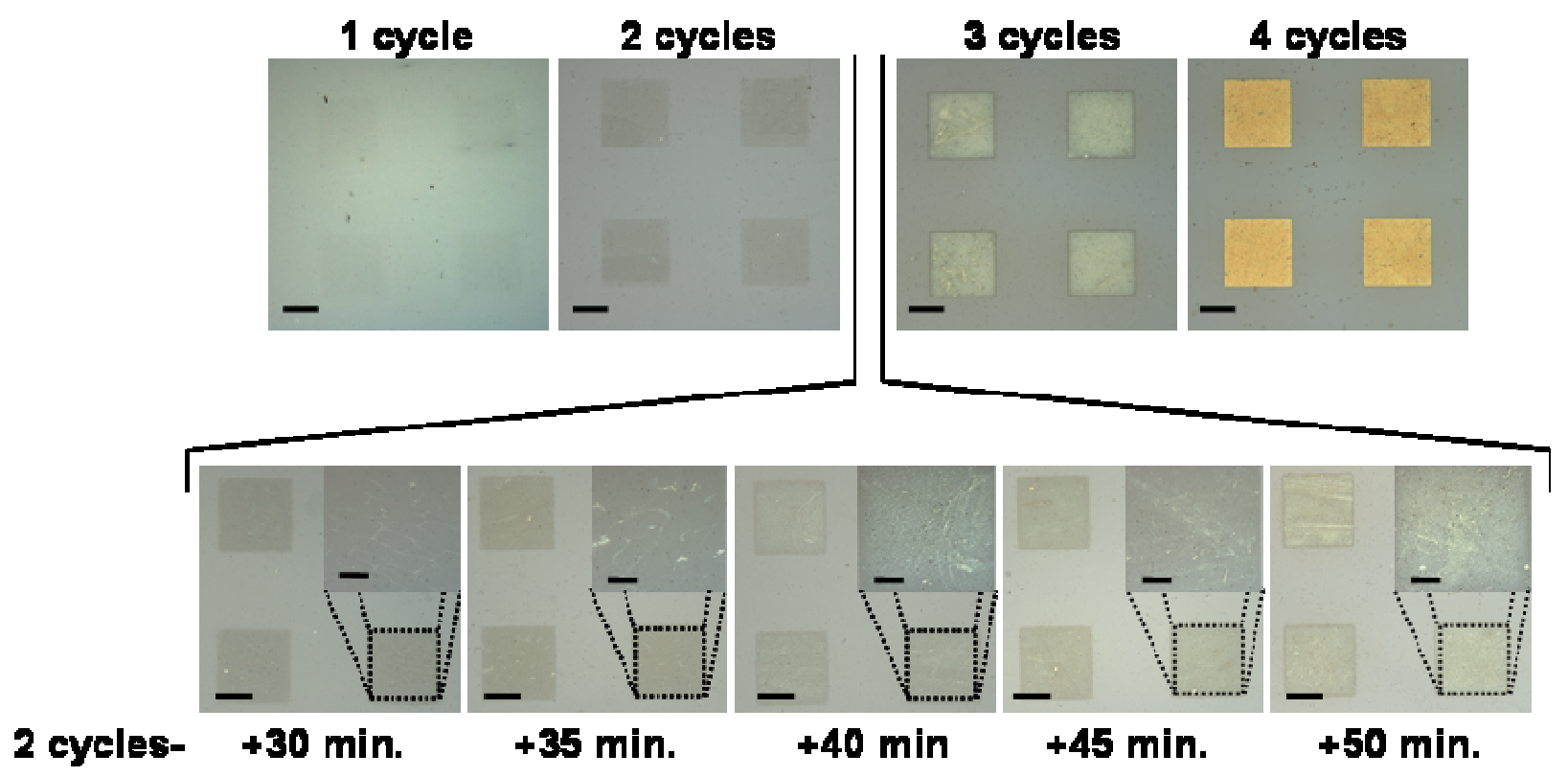

Supporting Figure S1. Optical micrographs showing the evolution of the CdS film growth through four deposition cycles. Main and inset scale bars are 50 and $20 \mu \mathrm{m}$, respectively. The films were grown from the solution containing $10 \mathrm{mM} \mathrm{CdCl}_{2}, 4.3 \mathrm{mM} \mathrm{HMT}$ and $15 \mathrm{mM}$ thiourea at $65{ }^{\circ} \mathrm{C}$. Each cycle involves 1 hour of deposition followed by a 10-second sonication in distilled water. The growing CdS films were also imaged in between the end of the $2^{\text {nd }}$ and $3^{\text {rd }}$ deposition cycles since there is significant change in the appearance of the film in this cycle. This series of images reveals a uniform increase in the density of the CdS films with deposition cycle (based on the color of the patterned films). No preferential initial deposition along the edges or at the center of the square CdS patch was observed. 


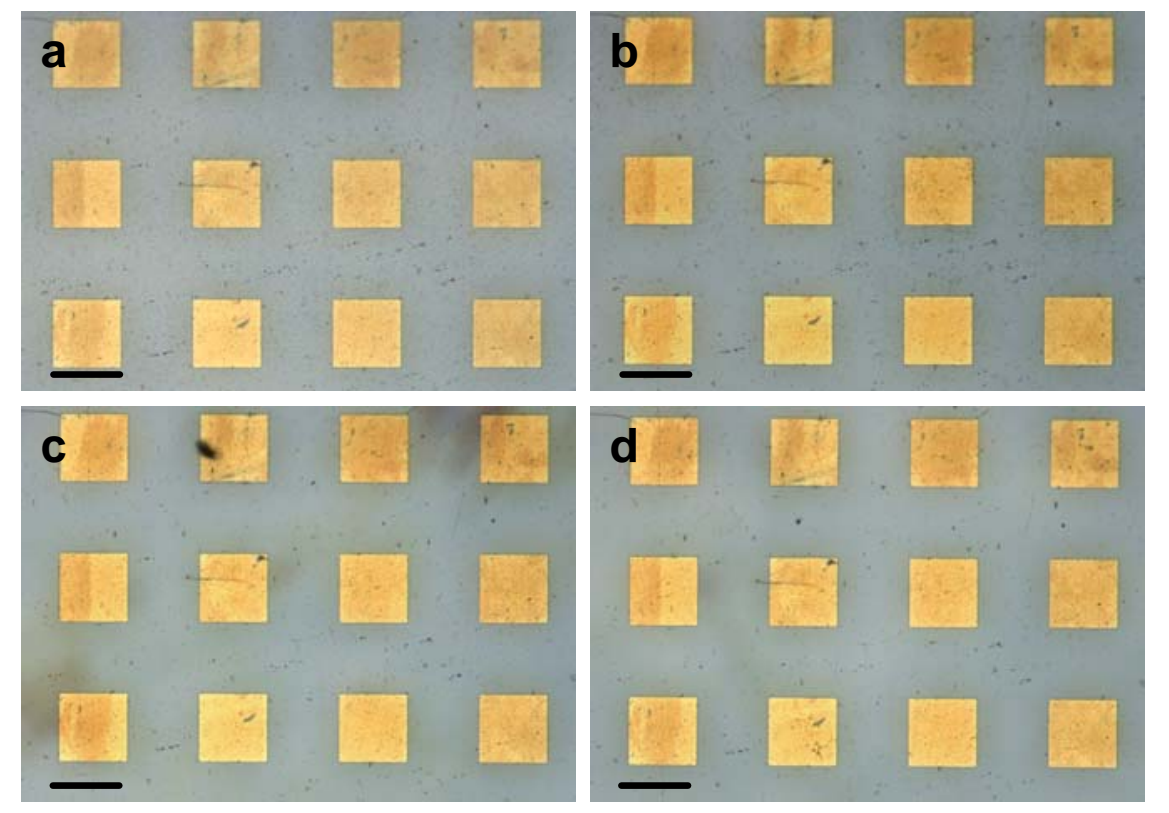

Supporting Figure S2. Optical micrographs showing the adherence of the CdS films on the PET substrate as analyzed using a simple Scotch tape peel-off test. The CdS films, which are grown from a solution containing $10 \mathrm{mM} \mathrm{CdCl}_{2}, 4.3 \mathrm{mM}$ HMT and $15 \mathrm{mM}$ thiourea at $65^{\circ} \mathrm{C}$, are subjected to 16 peel-off cycles. In each cycle, a fresh piece of clear Scotch tape is pressed onto the pattern, held for 10 seconds and then removed. Optical micrographs of the (a) as-grown CdS films along with the same films after (b) one, (c) six and (d) sixteen tape cycles are presented. There is no visible change in the quality of the patterned CdS, thus confirming good adhesion of the films on the polymer sheet. All scale bars are $100 \mu \mathrm{m}$.
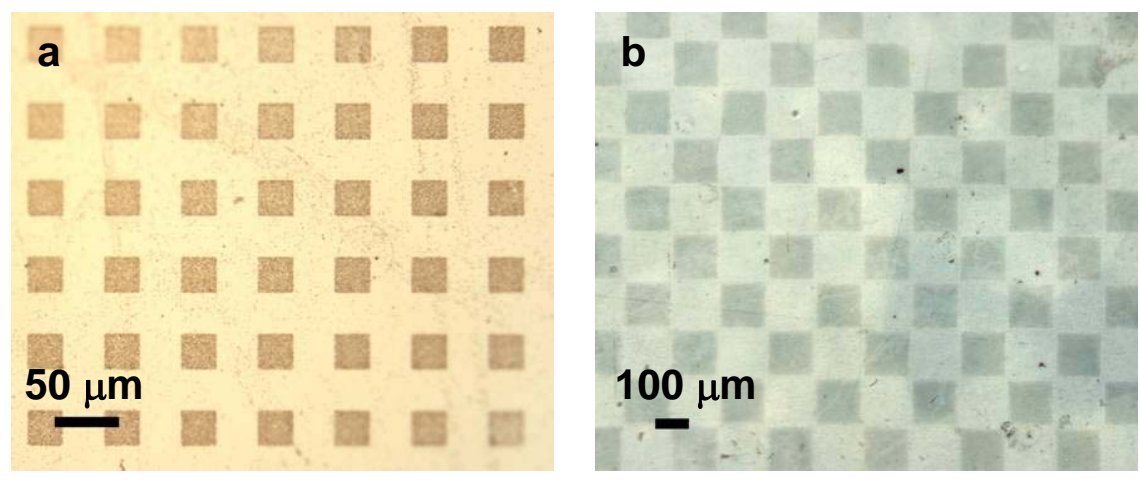

Supporting Figure S3. Optical micrographs of arrays of other inorganic functional materials selectively grown from solution on PET substrates using very similar procedures: (a) copper sulfide in a square pattern and (b) nickel sulfide in a checkerboard pattern. 

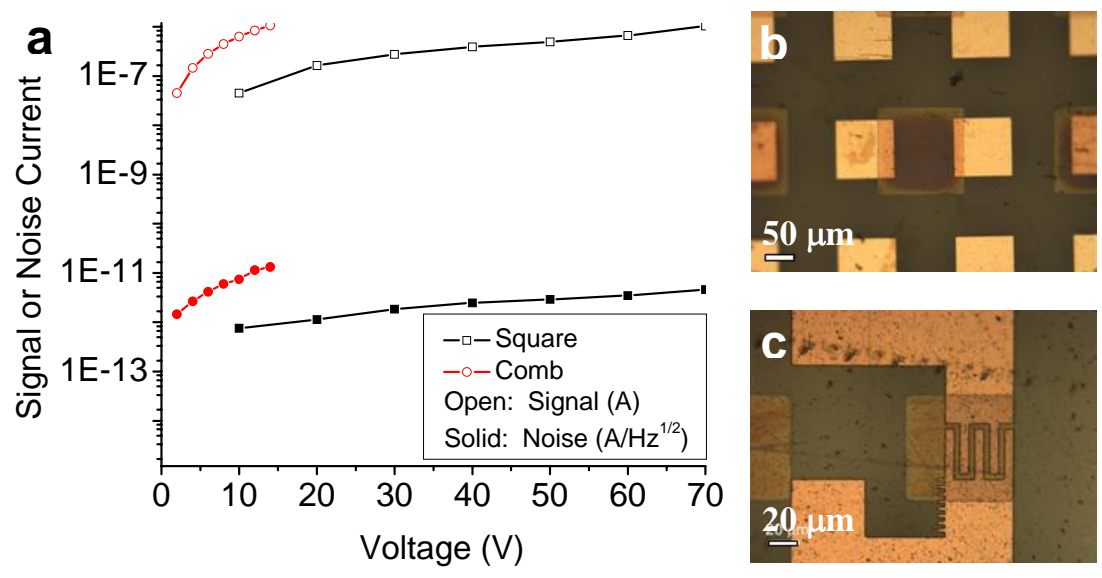

Supporting Figure S4. Comparison of different photodetector electrode configurations using CdS films that was grown from a solution containing $10 \mathrm{mM} \mathrm{CdCl}_{2}, 4.3 \mathrm{mM} \mathrm{HMT}$ and $10 \mathrm{mM}$ thiourea at 65 ${ }^{\circ} \mathrm{C}$. The values of the signal and noise currents seen in (a) for the (b) square and (c) interdigitated electrodes are not significantly different. Since $D^{*}$ is normalized with respect to the active area of the detector $\left(A_{d}\right)$, the calculated $D^{*}$ for the square and interdigitated electrodes are similar, as seen in Supporting Table S1.

\begin{tabular}{|c|c|c|}
\hline & Square & Interdigitated \\
\hline$I_{s, \text { max }}(\mu \mathrm{A})$ & 1.03 & 1.06 \\
\hline$I_{n}\left(\mathrm{pA} / \mathrm{Hz}^{1 / 2}\right)$ & 4.6 & 13.2 \\
\hline$A_{d}\left(\mathrm{~cm}^{2}\right)$ & 0.0001 & 0.0000057 \\
\hline$V(\mathrm{~V})$ at $I_{s, \text { max }}$ & 70 & 14 \\
\hline$D^{*}\left(\mathrm{~cm} \mathrm{~Hz}^{1 / 2} \mathrm{~W}^{-1}\right)$ & $1.0 \times 10^{10}$ & $3.8 \times 10^{9}$ \\
\hline
\end{tabular}

Supporting Table S1. Summary of the measured and calculated CdS device properties using different metal electrode configurations. The interdigitated electrodes used here has an advantage over the square electrodes because the former configuration needed $14 \mathrm{~V}$ to approach the lock-in amplifier threshold of $1.0 \mu \mathrm{A}$ signal current, compared to $70 \mathrm{~V}$ for the latter configuration while under a 17.8 $\mathrm{mW} / \mathrm{cm}^{2}$-irradiation. Hence the bias voltage required to obtain a high $\mathrm{D}^{*}$ is lower for the interdigitated configuration than the square electrode. 